\title{
Prior Hormone Therapy
}

National Cancer Institute

\section{Source}

National Cancer Institute. Prior Hormone Therapy. NCI Thesaurus. Code C16175.

An indication that an individual has been previously treated with hormonal therapy. 